\title{
Glutamate Neurotoxicity in Cortical Cell Culture
}

\author{
Dennis W. Choi, Margaret Maulucci-Gedde, and Arnold R. Kriegstein \\ Department of Neurology, Stanford University Medical Center, Stanford, California 94305
}

The central neurotoxicity of the excitatory amino acid neurotransmitter glutamate has been postulated to participate in the pathogenesis of the neuronal cell loss associated with several neurological disease states, but the complexity of the intact nervous system has impeded detailed analysis of the phenomenon. In the present study, glutamate neurotoxicity was studied with novel precision in dissociated cell cultures prepared from the fetal mouse neocortex.

Brief exposure to glutamate was found to produce morphological changes in mature cortical neurons beginning as quickly as $90 \mathrm{sec}$ after exposure, followed by widespread neuronal degeneration over the next hours. Quantitative dose-toxicity study suggested an $E D_{50}$ of 50-100 $\mu \mathrm{M}$ for a 5 min exposure to glutamate. Immature cortical neurons and glia were not injured by such exposures to glutamate. Uptake processes probably do not limit GNT in culture, as the uptake inhibitor dihydrokainate did not potentiate GNT. Possibly reflecting the lack of uptake limitation, glutamate was found to be actually more potent than kainate as a neurotoxin in these cultures, a dramatic reversal of the in vivo potency rank order. Some neurons regularly survived brief glutamate exposure; these possibly glutamate-resistant neurons had electrophysiologic properties, including chemosensitivity to glutamate, that were grossly similar to those of the original population.

The amino acid glutamate is present at several millimolar concentration in mammalian central gray matter (Waelsch, 1951) and has a ubiquitous excitatory effect on central neurons (Curtis et al., 1960; Crawford and Curtis, 1964; Krnjevic, 1974), properties that support the current belief that glutamate is likely a major mammalian central excitatory neurotransmitter (DiChiara and Gessa, 1981). It is therefore somewhat surprising that glutamate is also a neurotoxin (Lucas and Newhouse, 1957; Olney, 1969; Coyle et al., 1981). Under normal circumstances, protective mechanisms presumably limit neuronal glutamate exposure and prevent toxicity, but a potential for pathogenesis is surely ever present. Glutamate neurotoxicity (GNT) has now been proposed to participate specifically in the ncuronal cell loss associated with a number of neurologic diseases, including Huntington's disease (Coyle and Schwarcz, 1976; McGeer and McGeer, 1976), olivopontocerebellar atrophy (Plaitakis et al.,

Received Feb. 25, 1986; revised June 12, 1986; accepted July 23, 1986.

We thank M. Yokoyama for expert technical assistance. This work was supported by Grants BRSG RR5353 and NS21628 from the National Institute of Health, grants from the Wills and Hereditary Disease Foundations, and a Hartford Fellowship (to D.W.C.) from the John A. Hartford Foundation.

Correspondence should be addressed to Dennis $W$. Choi at the above address. Copyright (c) 1987 Society for Neuroscience $0270-6474 / 87 / 020357-12 \$ 02.00 / 0$
1982), epilepsy (Nadler et al., 1978; Sloviter, 1983), stroke (Rothman, 1984; Simon et al., 1984), and hypoglycemic encephalopathy (Wieloch, 1985). Despite this potential clinical importance, little is presently known about the phenomenon of GNT at the cellular level. The major obstacle to the study of GNT has been the complexity of the intact nervous system; indeed, it is somewhat problematic to demonstrate the phenomenon at all in vivo. Systemic administration of glutamate to rodents generally produces brain lesions only in immature animals without a fully developed blood-brain barrier, and then predominantly only in the circumventricular regions (Olney, 1978). Although it is possible to produce brain lesions in adult animals by direct intraparenchymal administration (McBean and Roberts, 1984), extremely high doses are needed, possibly reflecting the protective efficacy of glutamate uptake systems. Much of what we presently know about GNT is therefore derived indirectly, from studies of the structural analog kainate, a plant compound not endogenous to the mammalian CNS.

The purpose of this study, and of the companion study reported in the following paper, was to investigate the phenomenon of GNT directly, utilizing the experimental leverage gained in a primary dissociated cell culture system, derived from fetal mouse neocortex. In cell culture, defined concentrations of glutamate can be delivered directly to neurons in a controlled environment, and the resultant morphological changes can be precisely monitored in a serial fashion. We report here that glutamate is a remarkably potent and rapidly acting neurotoxin in cortical cell culture.

\section{Materials and Methods}

Cell culture. Dissociated murine cortical cell cultures were prepared using minor modification of an established technique (Dichter, 1978). Whole cerebral neocortices were removed from fetal mice (14-17 d gestation), taking care to discard the hippocampal formation, basal ganglia, and most of the meninges. The tissue was then minced, incubated in $0.08 \%$ acetylated trypsin for $45-75 \mathrm{~min}$ at $37^{\circ} \mathrm{C}$, dissociated by trituration, and plated as a single-cell suspension on Primaria (Falcon) 35 $\mathrm{mm}$ dishes $\left(10^{6}\right.$ cells/dish) in a plating medium of Eagle's minimal essential media (MEM, Earle's salts) supplemented with $10 \%$ heat-inactivated horse serum, $10 \%$ fetal bovine serum, glutamine (total $2 \mathrm{~mm}$, added the week of use), glucose (total $21 \mathrm{~mm}$ ), and bicarbonate (total $38 \mathrm{~mm}$ ). Cultures were maintained at $37^{\circ} \mathrm{C}$ in a humidified $9 \% \mathrm{CO}_{2}$ atmosphere. After 5-7 d in vitro, non-neuronal cell division was halted by 1-3 d of exposure to $10^{-5} \mathrm{M}$ cytosine arabinoside, and the cells were shifted into a maintenance medium similar to the plating media but lacking fetal serum. Subsequent media replacement was carried out on a biweekly schedule. The culture media used did not contain any glutamate except for that present in the serum (Hyclone defined sera); based on the supplier's measurements of serum glutamate levels, the initial glutamate concentration in maintenance media was less than $20 \mu \mathrm{M}$.

Cortical glial cell cultures were prepared using the same protocol as above but using cortices removed from early postnatal mice (postnatal days 1-3) instead of fetal mice, since neurons removed from such older 


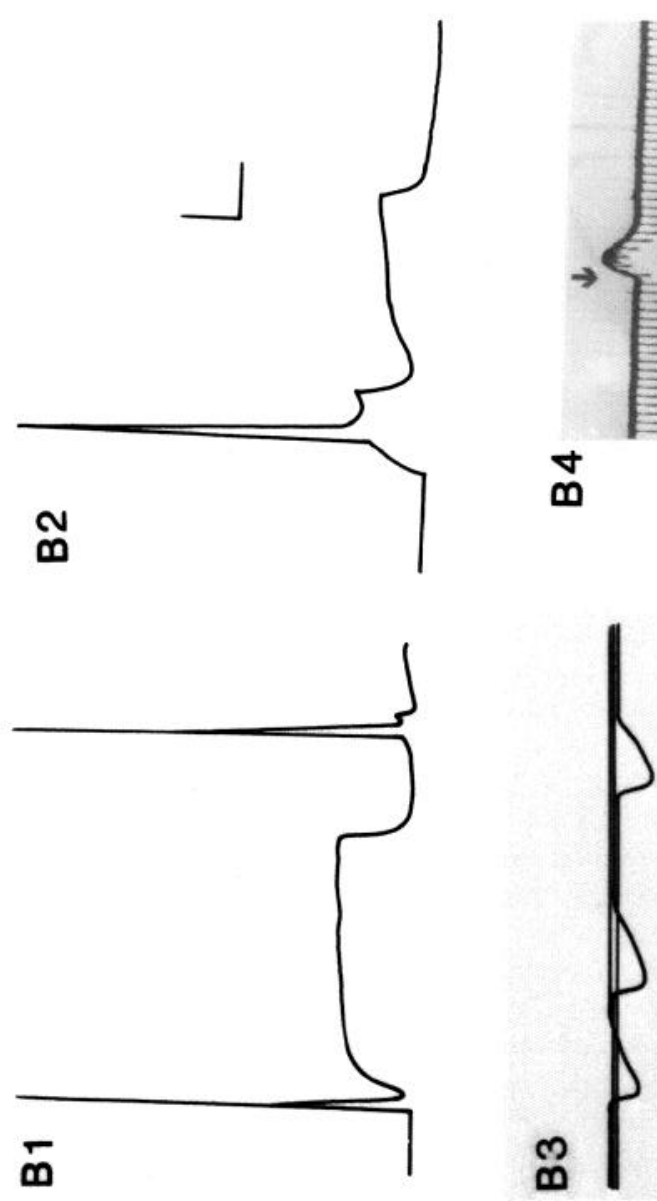

乌

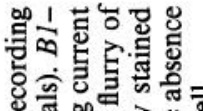

这.

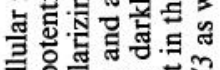

₹

突.

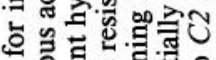

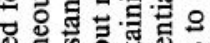

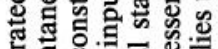

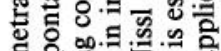

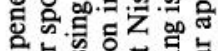

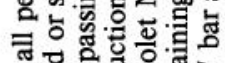

记

인

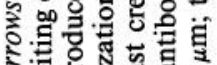

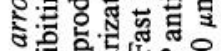

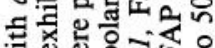

잉

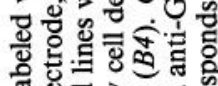

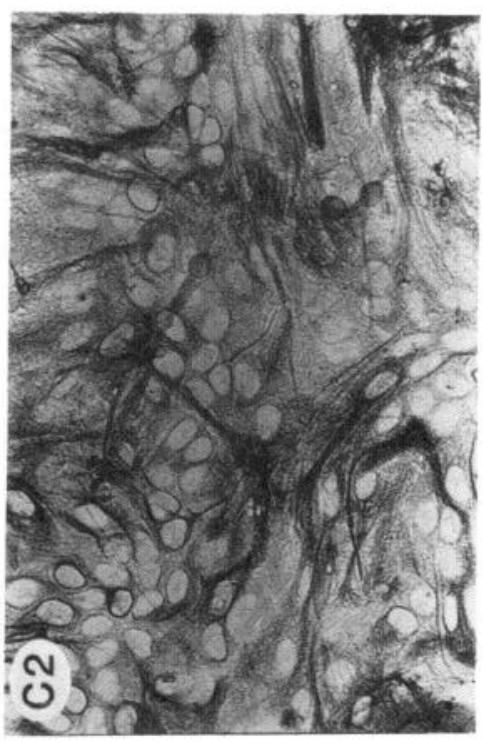

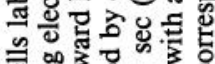

美

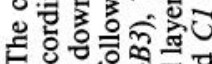

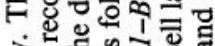

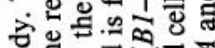

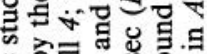

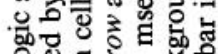

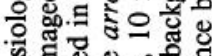

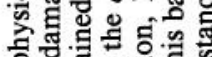

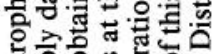

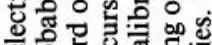

$\circ$ 边

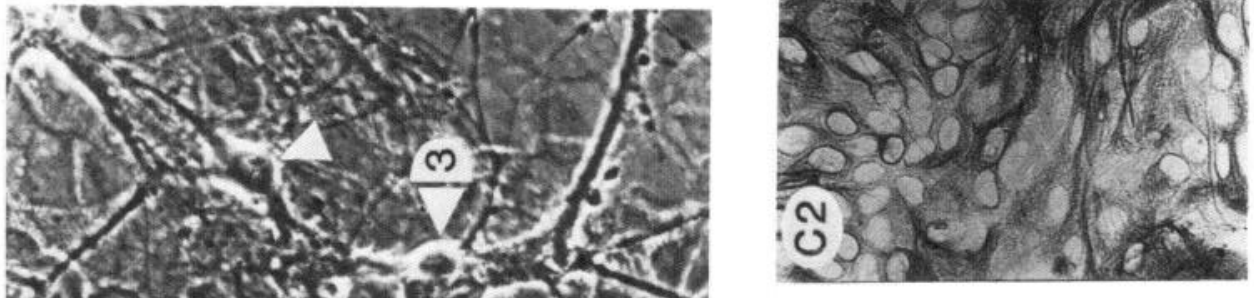

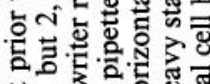

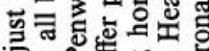

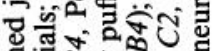

के

แั山.

요요

ते

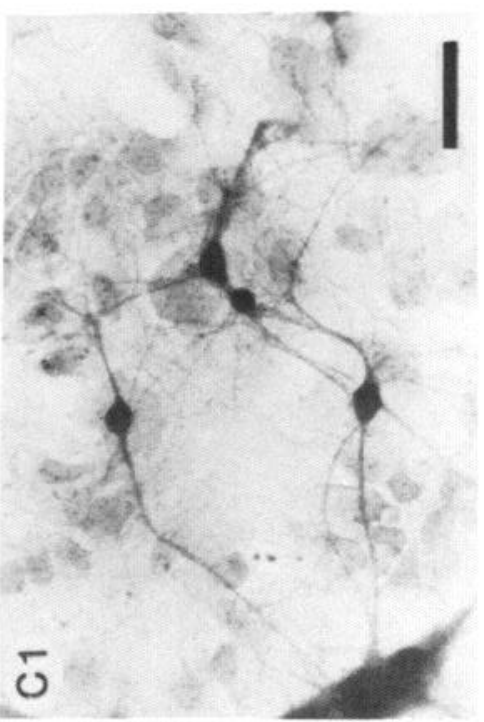

击

ชี

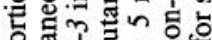

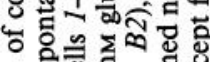

믕 कo

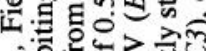

स융영 줄

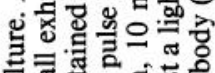

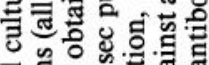

承

ब记

E

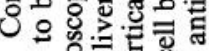

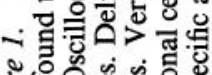

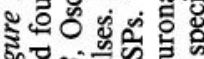

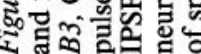



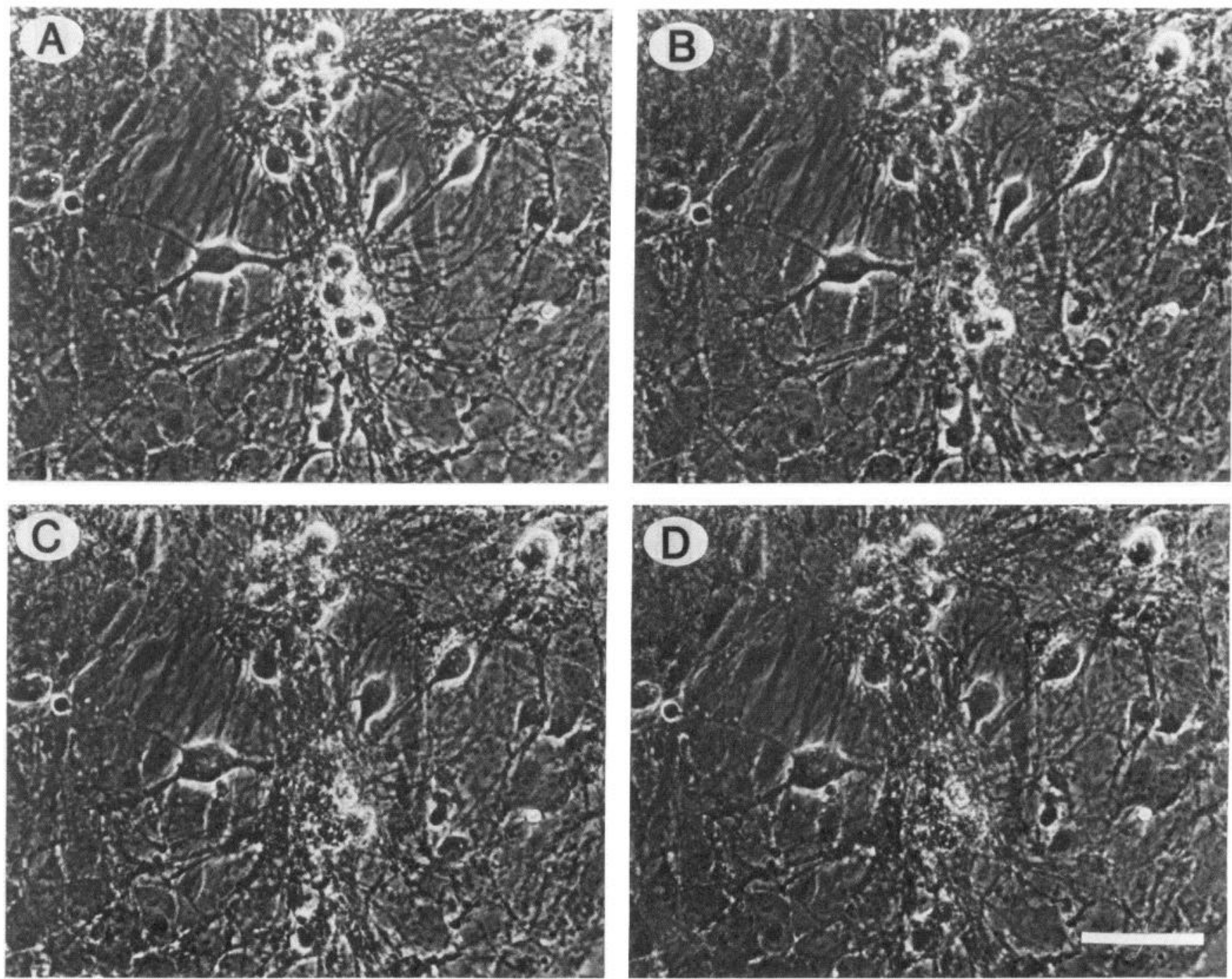

Figure 2. Acute time course of GNT. Serial phase-contrast micrographs showing a field of cortical cells before $(A)$, immediately after $(B)$, 10 min after $(C)$, and $25 \mathrm{~min}$ after $(D)$ exposure to a single $90 \mathrm{sec}$ pulse of $1 \mathrm{~mm}$ glutamate. The dish was maintained on the stage of the physiology microscope, and the field was continuously observed after glutamate was delivered by pressure ejection from a puffer pipette placed in the middle of the field. Bar, $50 \mu \mathrm{m}$.

animals do not survive the plating period (Booher and Sensenbrenner, 1972; McCarthy and deVellis, 1980).

Glutamate exposure. Prior to study, culture dishes were examined under phase-contrast microscopy, and (in most experiments) $1-5$ representative $200 \times$ microscope fields per dish were photographed and marked on a coordinate system. Exposure to glutamate was generally carried out at room temperature in a Tris-buffered "control salt solution" (CSS) substituted for culture medium by triple exchange; CSS had the following composition (in $\mathrm{mM}$ ): $\mathrm{NaCl}, 120 ; \mathrm{KCl}, 5.4 ; \mathrm{MgCl}_{2}, 0.8$; $\mathrm{CaCl}_{2}$, 1.8; Tris- $\mathrm{Cl}\left(\mathrm{pH} 7.4\right.$ at $25^{\circ} \mathrm{C}$ ); glucose, 15. After $5 \mathrm{~min}$, the glutamate was washed out thoroughly (effective dilution $>600$ ) and replaced with Eagle's MEM with augmented glucose $(21 \mathrm{mM})$ and $\mathrm{Na}$ bicarbonate $(38 \mathrm{~mm})$, prior to returning the dishes to the $9 \% \mathrm{CO}_{2}$ incubator. Continuous monitoring of $\mathrm{pH}$ with phenol red indicator was done in some experiments and did not show evidence of any $\mathrm{pH}$ disturbance with the procedure. Cultures were later removed from the incubator and reexamined at specified intervals, with follow-up photos taken of previously identified fields.

For quantitative assessment of GNT, cell counts were made from photomicrographs of representative identified fields taken before and after glutamate exposure; in most cases, the follow-up photomicrograph was taken both with phase-contrast and with bright-field following 5 min of incubation in $0.4 \%$ trypan blue, a dye normally excluded by healthy cells. Specific neurons present on the baseline photographs, but either absent or labeled with trypan blue on the follow-up study, were counted as damaged by glutamate; the counts were expressed as a percentage of the number of cells originally present. In control experiments, dishes exposed to the procedure described above, but without addition of glutamate, showed damage to no more than a few percent of neurons.

Immunohistochemical staining for glial fibrillary acidic protein (GFAP). Cultures to be stained were washed in CSS and fixed by immersion in Perfix (Fisher Scientific) for $30 \mathrm{~min}$ at room temperature. Fixative was removed by rinsing 3 times with $20 \mathrm{~mm}$ PBS (pH 7.5). Cultures were exposed first to a blocking solution consisting of $1.8 \%$ normal goat serum in PBS for $1 \mathrm{hr}$, followed by overnight incubation with polyclonal rabbit anti-GFAP antiserum (kindly supplied by Dr. Larry Eng) at $5^{\circ} \mathrm{C}(1: 250$ dilution of antiserum in blocking solution plus $0.3 \%$ Triton X-100). After a 60 min PBS wash (3 exchanges), cultures were processed for antibody binding with the avidin-biotin-peroxidase system (Vectastain ABC Kit, Rabbit IgG, Vector Laboratories) and reacted with $0.05 \mathrm{mg}$ / $\mathrm{ml}$ diaminobenzidine tetrahydrochloride (Sigma) for $10 \mathrm{~min}$ or until stained. Controls were processed in an identical manner except that anti-GFAP was omitted from the primary antibody solution.

Electrophysiology. Dishes were maintained on the stage of an inverted Nikon Diaphot microscope, in a warmed aluminum block (bath temperature, $33^{\circ} \mathrm{C}$ ), and perfused continuously with a recording medium consisting of 3 parts Earle's balanced salt solution and 1 part MEM, augmented with extra $\mathrm{CaCl}_{2}$ (total $3.8 \mathrm{~mm}$ ). Visualized cells (phase- 

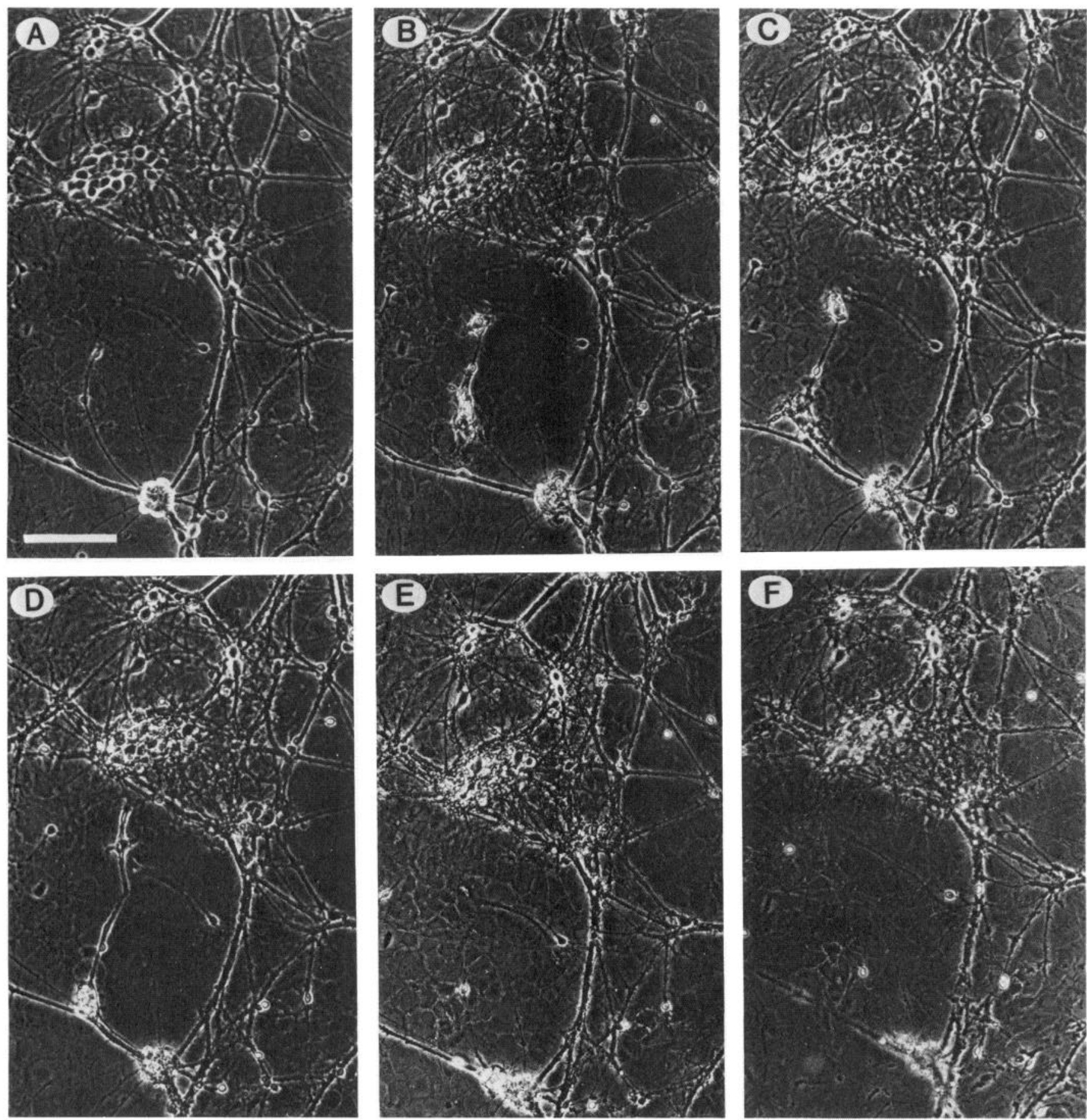

Figure 3. Long-term course of GNT. Serial phase-contrast micrographs of an identified field of cortical cells taken before $(A), 1 \mathrm{hr}$ after $(B), 2 \mathrm{hr}$ after $(C), 4 \mathrm{hr}$ after $(D), 9 \mathrm{hr}$ after $(E)$, and $24 \mathrm{hr}$ after $(F)$ pulse exposure to $0.5 \mathrm{~mm}$ glutamate for 5 min. Between photographs the dish was kept in the incubator. Bar, $100 \mu \mathrm{m}$.

contrast, $400 \times$ ) were impaled for intracellular recording with glass microelectrodes filled with $4 \mathrm{M}$ potassium acetate (50-80 M $)$, and the signal was displayed on a storage oscilloscope and a chart recorder. A bridge circuit enabled current to be injected through the recording electrode for the purpose of stimulation or measurement of cell input resistance. Defined concentrations of glutamate were delivered to cells by pressure ejection from a nearby "puffer" pipette, using the recording medium as a drug carrier (Choi and Fischbach, 1981).

\section{Results}

In murine cortical cell cultures prepared as described, presumptive neurons send out an extensive network of processes, and, over the first $10 \mathrm{~d}$ in culture, develop increasingly large, phase-bright cell bodies; such cells stain darkly with a Nissl stain (fast cresyl violet) (Fig. $1 C 1$ ). The background mat of cells 

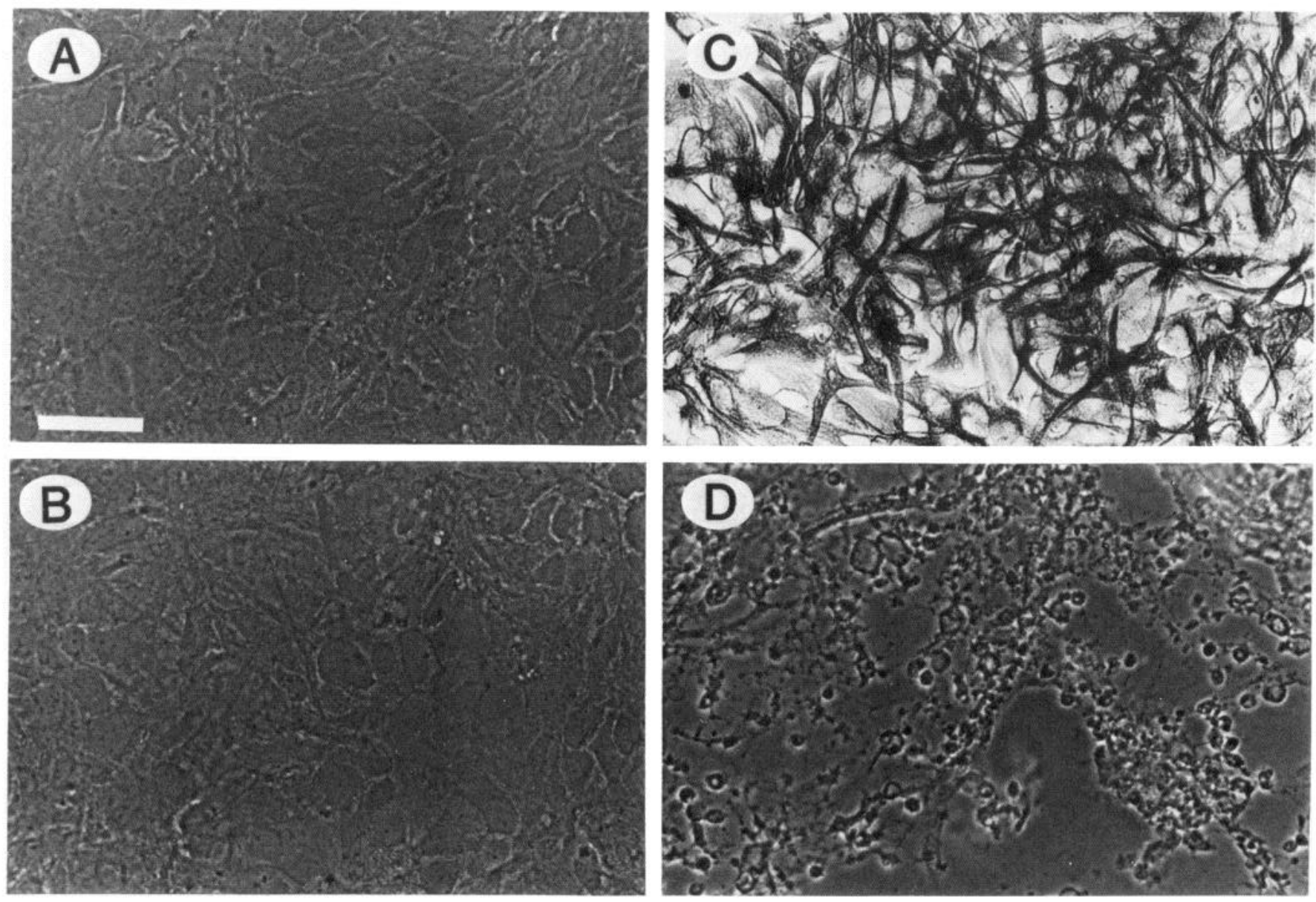

Figure 4. Lack of gliotoxicity of glutamate. $A$ and $B$, Phase-contrast micrographs of a representative field of a cortical non-neuronal cell culture taken before $(A)$ and $1 \mathrm{~d}$ after $(B)$ exposure to $0.5 \mathrm{~mm}$ glutamate for $5 \mathrm{~min}$. $C$, bright-field micrograph of a sister non-neuronal culture stained for GFAP. $D$, Phase-contrast appearance of another sister culture $1 \mathrm{~d}$ after exposure to $80 \mu \mathrm{M} \mathrm{A23187}$ in the presence of high (6.8 mM) Ca for 20 min; only debris is apparent. A23187 was first dissolved in dimethyl sulfoxide. Bar, $50 \mu \mathrm{m}$.

for the most part showed the typical flat, polygonal morphology of astrocytes in culture (Booher and Sensenbrenner, 1972; McCarthy and deVellis, 1980) and stained positively with rabbit anti-GFAP (Fig. 1, C2, C3).

The neuronal identity of these phase-bright cells was confirmed by intracellular recordings (Fig. $1, A, B$ ). In a series of 45 cells with stable membrane potentials equal to or more negative than $-50 \mathrm{mV}$, all had spontaneous or stimulus-evoked neuronal action potentials, and most (42/45) exhibited spontaneous excitatory and/or inhibitory synaptic activity. Resting potential was $60.6 \pm 6.7 \mathrm{mV}$ and input resistance was $73.9 \pm$ $30.7 \mathrm{M} \Omega$ (mean $\pm \mathrm{SD})$. Brief $(1-2 \mathrm{sec})$ pressure ejection of $0.5-$ $1.0 \mathrm{~mm}$ glutamate from a puffer pipette $20-50 \mu \mathrm{m}$ distant from a neuronal cell body was invariably followed by reversible membrane depolarization and reduction in input resistance $(27 / 27$ cells) (Fig. 1B4); in most cases a brief burst of synaptic potentials/action potentials was also seen.

If the pressure ejection of glutamate was not terminated after a few seconds, but maintained for a minute or longer, neurons near the puffer electrode were seen to swell, darken, and become more granular. These changes were often detectable as early as 1-2 min after onset of glutamate exposure and continued to evolve after the ejection pulse was terminated. Figure 2 shows serial phase-contrast photomicrographs of a field of cortical neurons taken before and after pressure ejection of glutamate; 90 sec after exposure onset (Fig. $2 B$ ), 1 neuronal cell body (in the center of the photo, at the top of the cluster of 4 neurons) had already swollen by about $20 \%$ in diameter.

In order to study the late effects of glutamate exposure, the bath application procedure described in Materials and Methods was used. Pulse exposure of mature (14-24 d in vitro) cultures to $0.5 \mathrm{~mm}$ glutamate for $5 \mathrm{~min}$ in CSS was invariably followed by widespread progressive neuronal degeneration over subsequent hours; by the following morning, most of the neurons were replaced by debris ( $>50$ experiments; Fig. 3 ). Staining with dyes (fast cresyl violet, $0.4 \%$ trypan blue), as well as probing with microelectrodes, confirmed the cell-free nature of much of this debris visualized with phase-contrast. Neuronal cell counts performed on 14 representative $200 \times$ microscope fields in several separate experiments showed that $88.1 \pm 2.6 \%$ (SE) of specifically identified neurons were damaged or destroyed by this glutamate exposure. Interestingly, neurons in clumps (reaggregated from the original dispersed single-cell plating) tended to be more rapidly and more thoroughly destroyed by glutamate exposure than more isolated counterparts.

The morphology of the underlying astrocyte bed appeared 

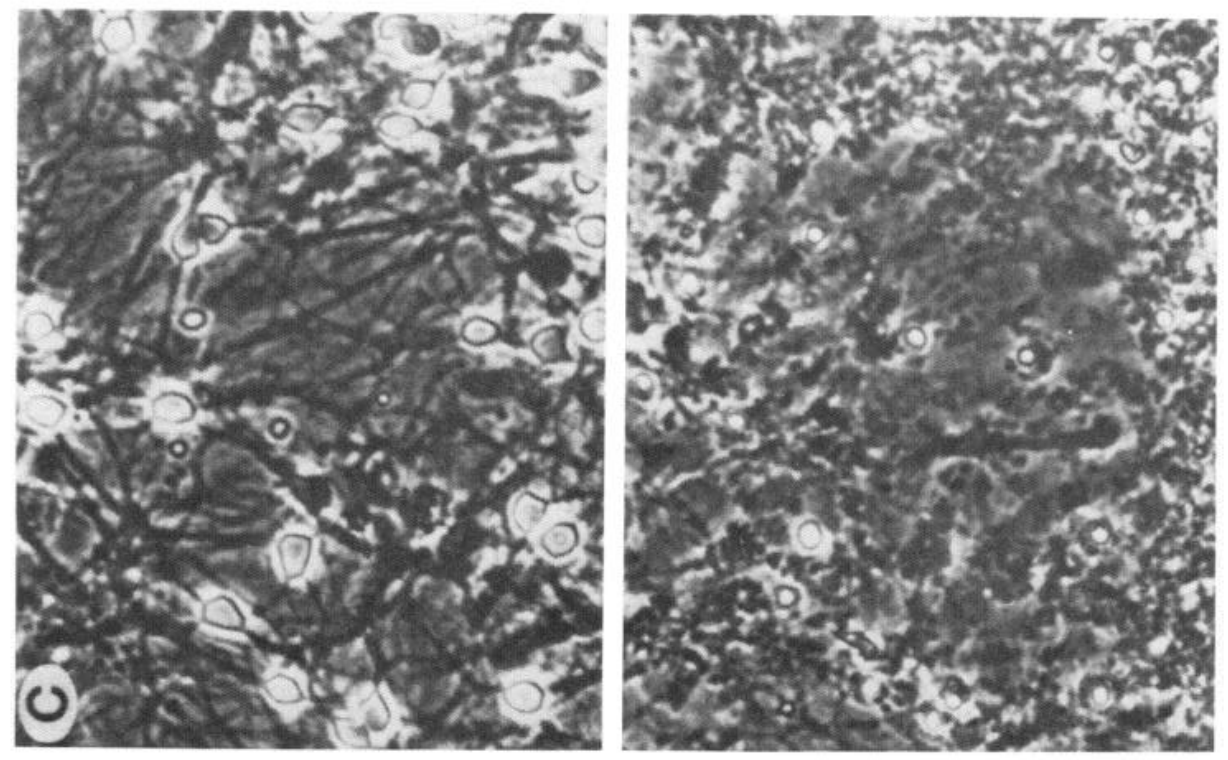

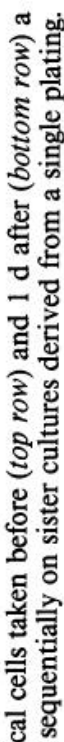
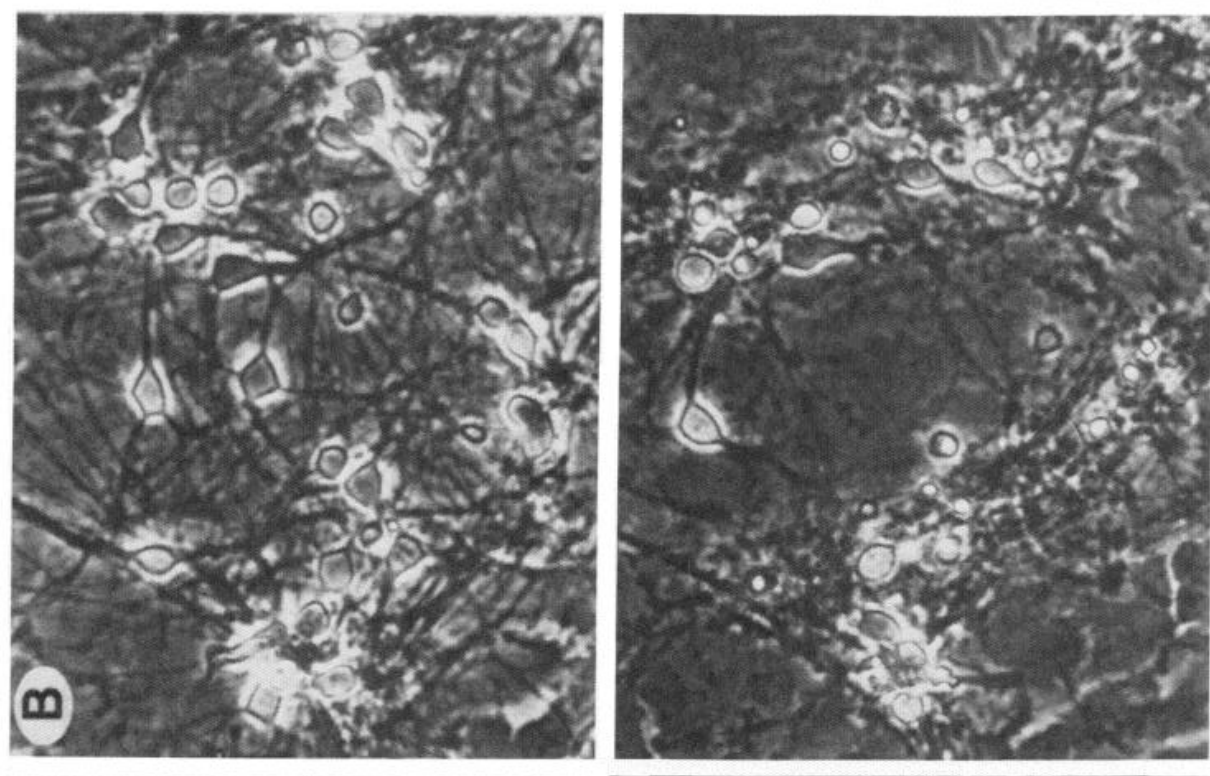

릉

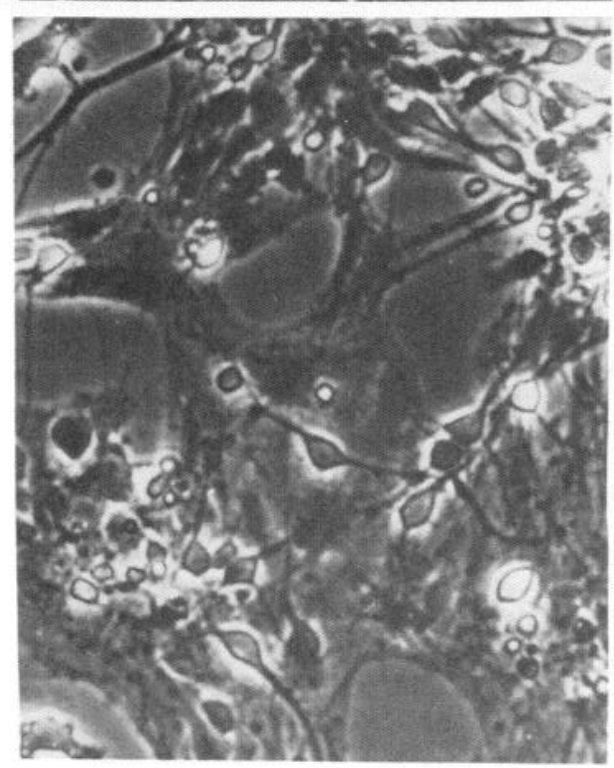

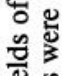

象

进

를

号

究完

鄯

ن

E뭄

密

岁

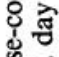

造

ㅎํำ

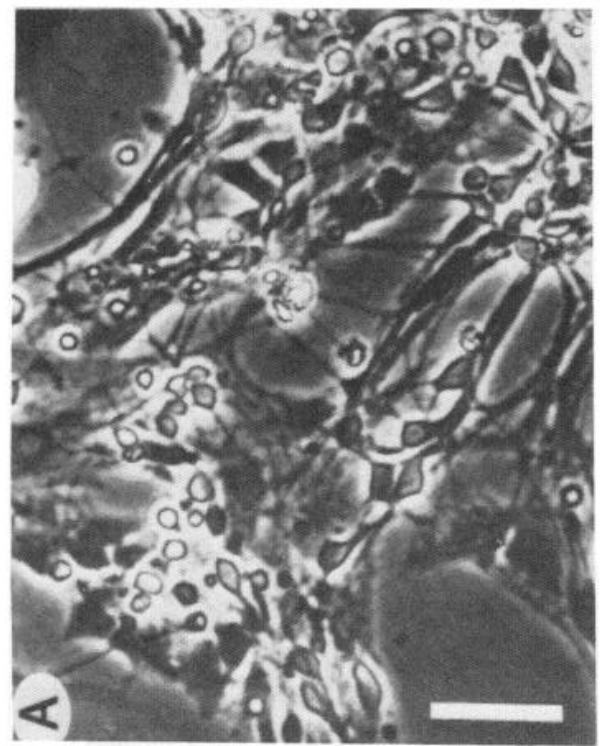

हर

品

돌

\%

สํํㅇ

동

형

बै

\%

ป

콩로

क्ष

音

政

a

它

ด

的家夆

우

部

的哭 
completely unaffected by such glutamate exposure and remained stable for days afterwards; virtually no staining of the glia was ever seen (> 30 experiments) following incubation in $0.4 \%$ trypan blue. A similar lack of glutamate effect was seen with the nearly pure astrocyte cultures prepared from postnatal cortices (Fig. 4, $A-C ; n=3$ ), in contrast to the complete glial disintegration that followed sufficient exposure to the $\mathrm{Ca}$ ionophore A23187 (Fig. $4 D ; n=3$ ). The rate of glucose disappearance from the culture medium of a glial culture exposed to glutamate did not differ from that of a control glial culture (the media glucose concentration in both dropped from $7 \mathrm{~mm}$ to undetectable over $4 \mathrm{~d}$ ), suggesting that glutamate exposure does not grossly alter glial glucose utilization.

The reliable neurotoxicity produced by exposure of cortical cultures to $0.5 \mathrm{~mm}$ glutamate for $5 \mathrm{~min}$ was only seen with mature cultures. Immature (5-7 d in vitro) cultures, characterized by small, phase-dark neurons and incomplete spreading of the glial mat, were unaffected by such glutamate exposure, and partial effects were seen with cultures of intermediate maturity (3 experiments; Fig. 5). This development of vulnerability to glutamate with increasing age in vitro was repeated twice with sister cultures from a single plating; neuronal cell counts obtained from 1 of these repeat experiments are presented in Figure 6.

The neurotoxicity produced by a $5 \mathrm{~min}$ exposure to glutamate increased with increasing concentrations of glutamate (Fig. 7). The $\mathrm{ED}_{50}$ was consistent among sister cultures of a given plating but varied somewhat between about 50 and $100 \mu \mathrm{M}$ among different platings. A quantitative determination of neuronal injury or loss versus glutamate concentration, measured on sister cultures of a single plating and representative of 2 other experiments, is presented in Figure 8.

The effective concentration of an acute pulse of bath-applied glutamate at neuronal cell membranes is probably not much reduced by the presence of uptake mechanisms in the open, 2-dimensional environment of dissociated cell culture. One might therefore expect that the neurotoxic potency of glutamate in cell culture might be increased compared to that found in vivo. On the other hand, kainate, a structural analog of glutamate that is not taken up by the mammalian CNS (Johnston et al., 1979), a characteristic that perhaps contributes to the fact that it is 2 orders of magnitude more potent than glutamate as a neurotoxin in vivo (Schwarcz et al., 1978), would not be expected to be more potent in culture than in vivo. To test the prediction that the glutamate/kainate neurotoxicity potency ratio would be increased in culture, the drugs were directly compared on sister cultures. In 4 such direct comparisons, $1 \mathrm{~mm}$ kainate was found to be actually less toxic than $0.5 \mathrm{~mm}$ glutamate (Fig. $9 A$ ). Neuronal cell counts corroborated this finding: $1 \mathrm{mM}$ kainate for 5 min was associated with the loss of only $13.0 \pm 8.5 \%$ (SE, $n=$ 6) of specifically identified neurons, compared with the $88.1 \pm$ $2.6 \%$ neuronal loss observed with $0.5 \mathrm{~mm}$ glutamate for $5 \mathrm{~min}$ (see above); different at $p<0.001,2$-tail $t$ test).

Furthermore, additional evidence that GNT in culture is not affected by uptake was that the toxicity of an intermediate concentration of glutamate $(60 \mu \mathrm{M})$ was not detectably altered by the addition of the glutamate uptake inhibitor dihydrokainate (DHK) (Johnston et al., 1979) at $1 \mathrm{~mm}$ to the exposure solution (Fig. 9, $B-D$ ). In control experiments, a 5 min exposure to 1 mM DHK alone did not injure neurons.

Although most neurons were destroyed by brief exposure to

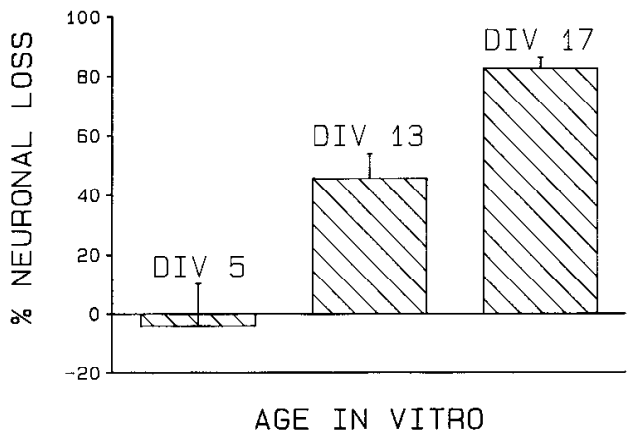

Figure 6. Quantitation of the development of glutamate neurotoxicity with age in vitro. At each specified age in vitro, a sister culture from a single plating was exposed to $0.5 \mathrm{~mm}$ glutamate for $5 \mathrm{~min}$, and the mean and SEM of the injury or loss to cortical neurons in 3 representative microscope fields, expressed as a percentage of the original cell count, are presented. At DIV 13 and DIV 17, counts were performed on specifically identified neurons as described in Materials and Methods; however, at DIV 5, the cultures were changing too rapidly to permit unambiguous recounting of previously identified cells, so absolute counts at selected locations in the dish were compared. (In fact, in 1 field, substantially more neurons were found at the selected location $24 \mathrm{hr}$ after glutamate exposure than were originally present, accounting for the presentation of a negative mean cell loss.)

$0.5 \mathrm{~mm}$ glutamate, in almost all cases a considerable number of apparently intact neurons could be found a day after exposure (nearly $12 \%$ of the identified neurons in the cell counts presented above; Figs. 9, 10A). These surviving cells excluded trypan blue (Fig. 1OB) and remained morphologically stable for at least several more days. Electrophysiologic study of 8 such surviving cells (Fig. 10, C, D) showed no gross differences in resting potential $(63.3 \pm 6.5 \mathrm{mV}$, mean $\pm \mathrm{SD})$, input resistance $(74.8 \pm$ $39.7 \mathrm{M} \Omega$ ), excitability ( $8 / 8$ cells), or response to $0.5-1 \mathrm{~mm}$ glutamatc ( $7 / 7$ cells depolarized) compared to control neurons (see above). Interestingly, $7 / 8$ of the cells still exhibited spontaneous synaptic activity, a surprisingly high percentage given the recent massive neuronal loss; this may suggest the existence of a high density of synaptic interconnections in these cultures.

\section{Discussion}

The present experiments establish that glutamate is a remarkably potent, rapidly acting neurotoxin in cortical cell culture, and they exploit the accessibility of culture to define the first quantitative concentration-effect relationship for GNT on cortical neurons. The observed $\mathrm{ED}_{50}$ of $50-100 \mu \mathrm{M}$ is near the $\mathrm{ED}_{50}$ of 100-300 $\mu \mathrm{M}$ reported by Brookes and Burt (1980) for GNT on spinal cord neurons. The concentration of glutamate required to kill a large percentage of the in vitro cortical neuronal population after $5 \mathrm{~min}$ of exposure $(100 \mu \mathrm{M})$ is only $1 / 100$ th of the $10 \mathrm{~mm}$ concentration normally present in whole cortex (Waelsch, 1951), and presumably a smaller fraction of the actual glutamate concentrations present in intracellular compartments. With exposures longer than $5 \mathrm{~min}$, even lower glutamate concentrations could possibly be toxic.

The present experiments also provide a novel degree of temporal resolution into the serial morphological changes in central neurons that follow in the wake of excess exposure to glutamate. The neuronal swelling seen after only $90 \mathrm{sec}$ of glutamate application is comparable to the rapid swelling of locust leg muscle reported within 5 min of exposure to glutamate (Duce et al., 

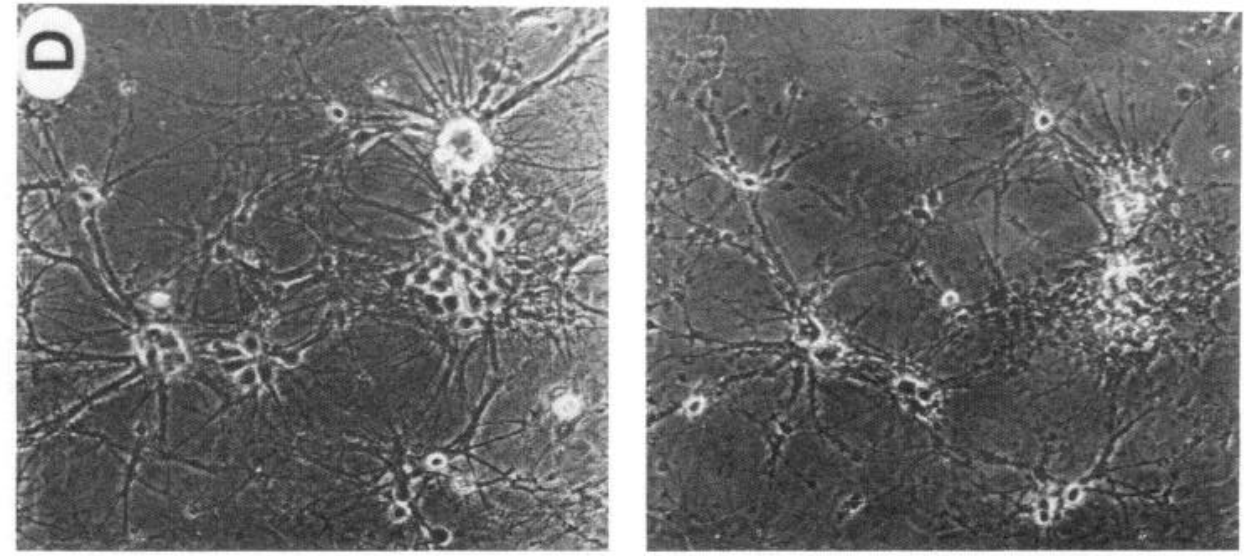

톨
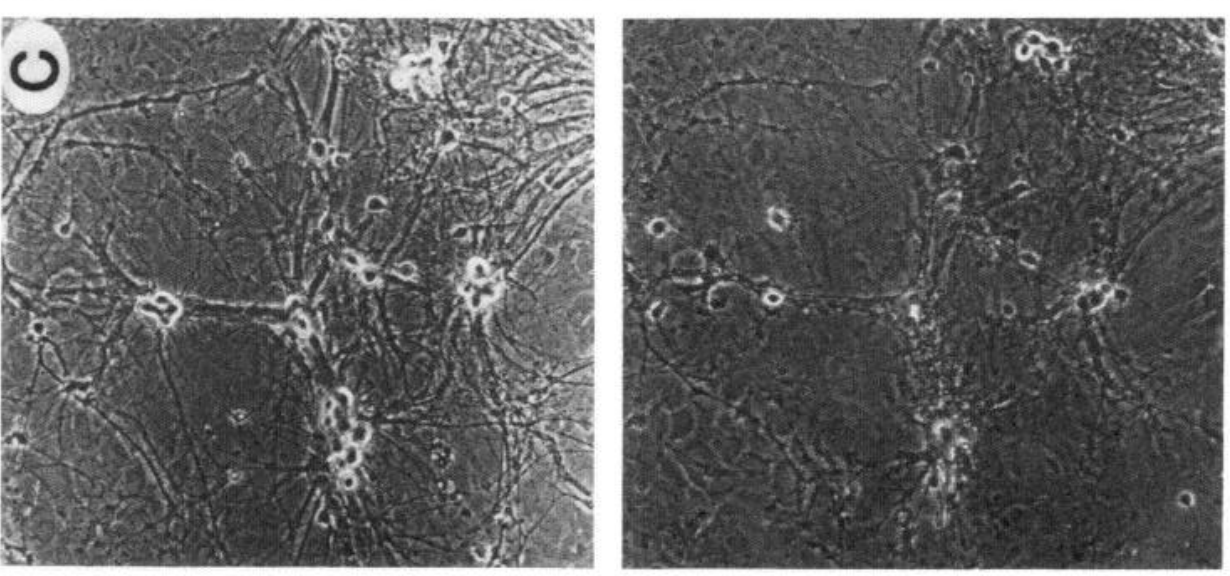

is

ำำ

亏ัญ

¿를

氖怨

ठक

드

范

亏ิ

s.

3

늄

8 品

ฮี.

웡

बึ

氙

边

웅

중

递

롤
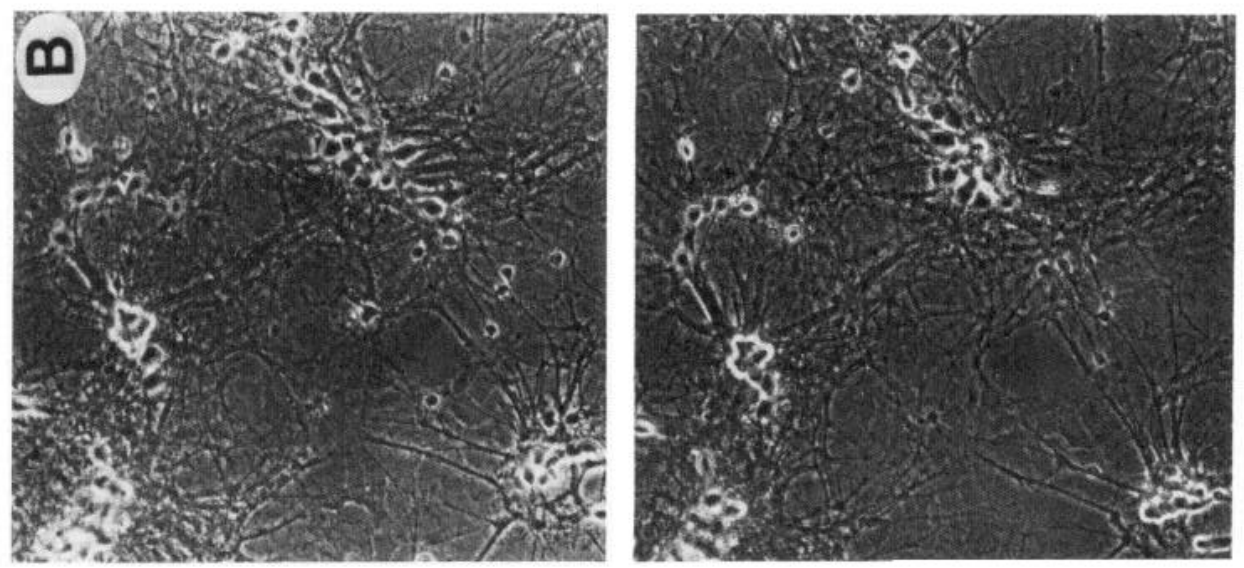

ㄴ-

年

담

ํㅗㅇ

붕

응

比

ठํํ

崩

के

它芒

즈으

둥

ฮै

讨
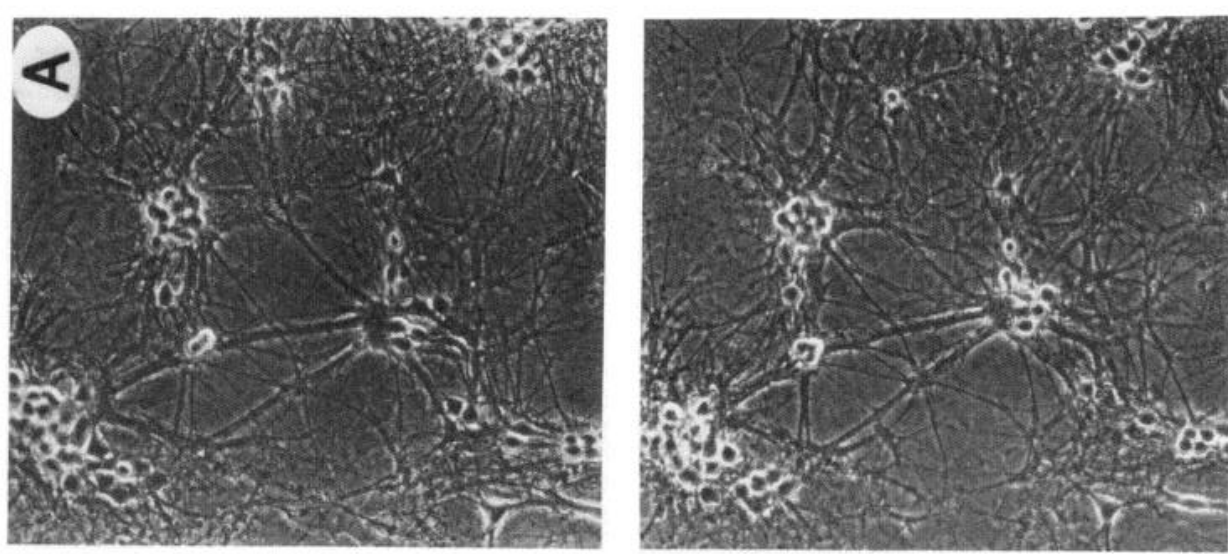

을

음

넝

ำ.

틍

콩

넝.

을

啊

웡

중

o

$\therefore$ 원

灵

5ิ

站 


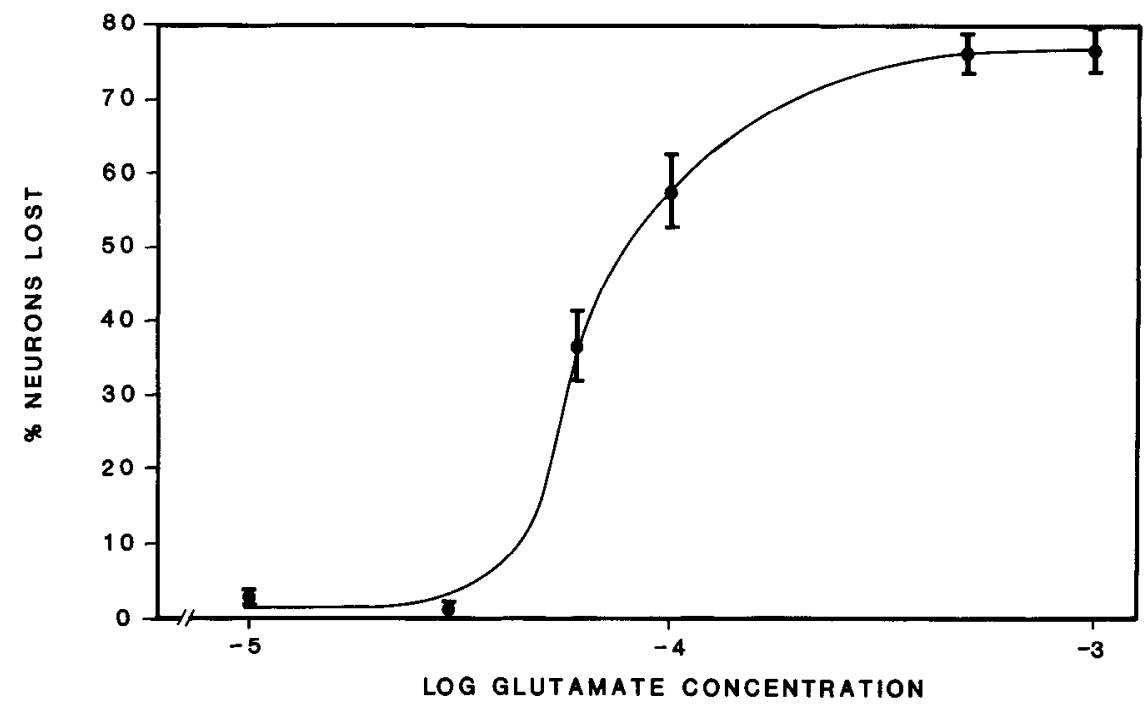

Figure 8. Dose-response relationship for glutamate neurotoxicity. At each tested concentration, the mean and SEM of cortical neuronal injury or loss in 3 identified fields are expressed as a percentage of the original cell count. The determinations were made in a single experiment on sister cultures and are typical of 2 other experiments. The small percentage of neuronal damage seen after exposure to $10-30 \mu \mathrm{M}$ glutamate is similar to that seen in control experiments without glutamate addition and, thus, may represent "natural" cell death in the cultures.
1983); previous in vivo observations have documented neuronal dendritic swelling only after 15-30 min (Coyle et al., 1981).

The potency ratio of glutamate relative to kainate as a neurotoxin in the present experiments was dramatically increased compared with that customarily found in vivo. This finding is similar to that reported by Brookes and Burt (1980) for spinal cord cells in culture, and by Garthwaite (1985) for cerebellar cells in culture but not with cerebellar cells in slice. As discussed above, a likely explanation for the finding is a heightened neurotoxic effect of glutamate in cell culture, due to the free access of bath glutamate to neuronal membranes in culture. The high vulnerability of cultured neurons to excess glutamate exposure may thus reflect the true intrinsic vulnerability of central neurons to GNT. Neurons in vivo are likely protected against prolonged glutamate exposure by both the blood-brain barrier and powerful neuronal and glial (McLennan, 1976; Schousboe, 1981) glutamate uptake systems. GNT in vivo may therefore only occur when these protective mechanisms are either impaired (e.g., a low-energy state reducing uptake function) or overwhelmed (Mangano and Schwarcz, 1983).

It is also possible that a lower neurotoxic potency of kainate in vitro may contribute to the observed reversal of the glutamate/ kainate potency ratio. The neurotoxic effect of kainate in vivo appears to depend in part on the presence of local glutamatergic terminals (Biziere and Coyle, 1978), perhaps because some of the neurotoxicity of kainate is produced by release of endogenous glutamate. Cell culture may lack the concentrated, highly organized glutamatergic projections found in those in vivo regions (e.g., striatum, hippocampal CAl) that are highly vulnerable to exogenously applied kainate.

No evidence of direct glutamate gliotoxicity was seen with the exposures to glutamate used here, either on glial elements in the mixed cortical cultures or in the essentially pure glial cultures prepared from postnatal animals. Swelling of glial and ependymal elements is seen with GNT in vivo (Olney, 1971), but with low doses of glutamate, neurotoxicity without gliotoxicity has been observed (Olney et al., 1971). Evidence of glutamate gliotoxicity has been observed in pure glial cultures prepared from chick retinal cells (Hyndman, 1984) but only with immature, proliferating glial cultures and with more intense glutamate exposure than used here ( $5 \mathrm{~mm}$ for days). The present study would therefore support the hypothesis (Nadler et al., 1980) that in vivo glutamate gliotoxicity is primarily an indirect effect secondary to neuronal damage, perhaps resulting from the accumulation of potassium or other substances in the closed extracellular spaces of intact tissue.

Besides the glia, immature neurons were also apparently resistant to GNT. The brain injury produced by parenteral kainate similarly is minimal in immature rats younger than age $18 \mathrm{~d}$ and then increases with maturation until the adult pattern is attained at age $35 \mathrm{~d}$ (Nitecka et al., 1984). The basis for the resistance of immature neurons to excitotoxins is not known; one possibility is that immature neurons have fewer membrane receptors for glutamate than mature neurons. The number of Na-independent glutamate binding sites in rat cerebral cortex increases dramatically between birth and age $50 \mathrm{~d}$ (Sanderson and Murphy, 1982).

It is interesting that some ncurons in culture do survive brief glutamate exposure. A subject for future study is whether these surviving neurons are a random sampling of the original population, surviving because of chance, or whether they represent a relatively resistant subpopulation of cortical neurons. Differential regional vulnerability to kainate is seen in several locations in vivo, including cochlear nucleus (Bird et al., 1978) and hippocampus (Nadler et al., 1978); even within a single brain region, some neurons do appear to be more vulnerable than others to injury by excitatory amino acids (Nadler et al., 1980; Kohler and Schwarcz, 1983).

No gross differences in resting potential or input resistance were seen between the surviving neurons studied and the original population. The simplest hypothesis, that the surviving neurons lack membrane glutamate receptors, is excluded by our direct demonstration of glutamate chemosensitivity on those cells. Additional study will be required to search for other cellular characteristics that are correlated with vulnerability to glutamate. Ferrante and colleagues (1985) have recently reported that a distinct subpopulation of striatal neurons containing the enzyme nicotinamide adenine dinucleotide phosphate disphorase are preserved in Huntington's disease; a search for such cells in cultures exposed to glutamate seems warranted (see Note added in proof). In the following paper, we report evidence that GNT may be mediated largely by a calcium influx; thus, a 

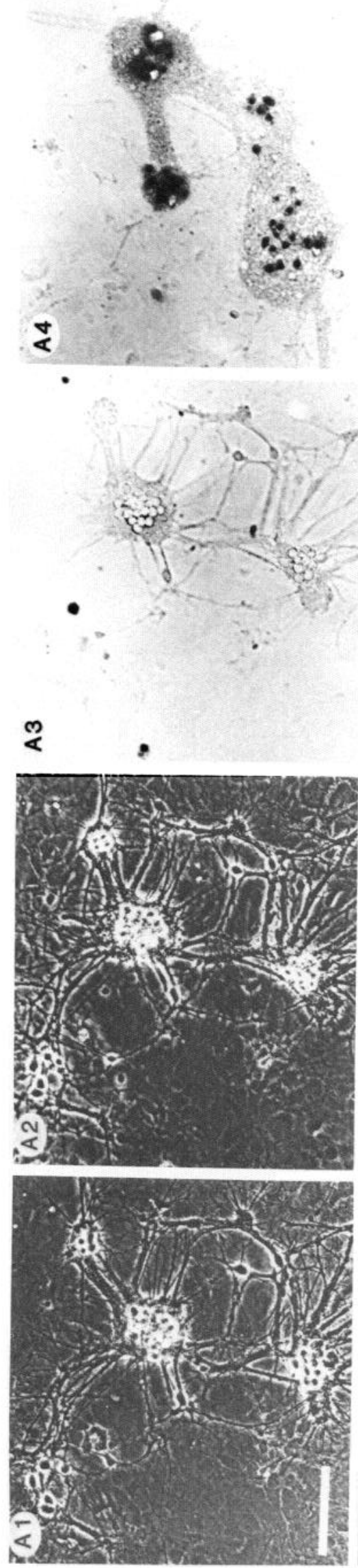

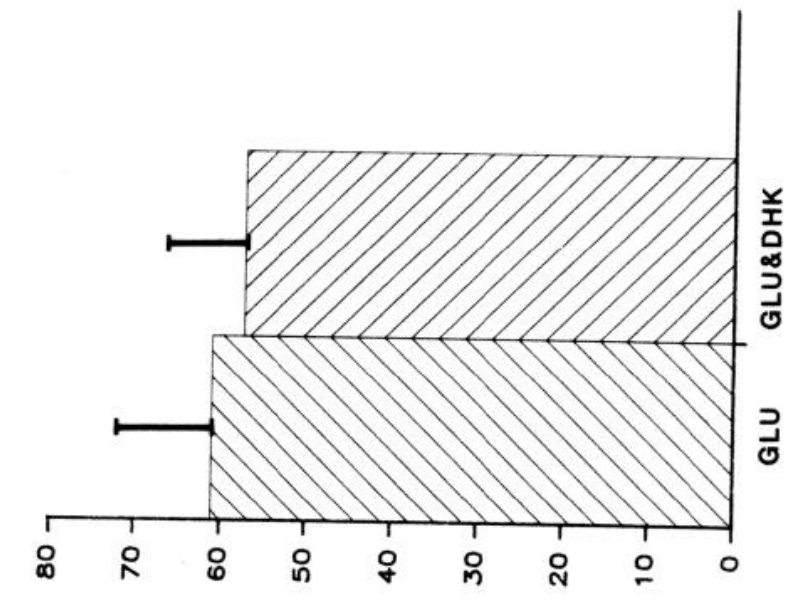

S४H $\succcurlyeq 乙 \perp \forall \perp S O 7$ SNOYNJN \%
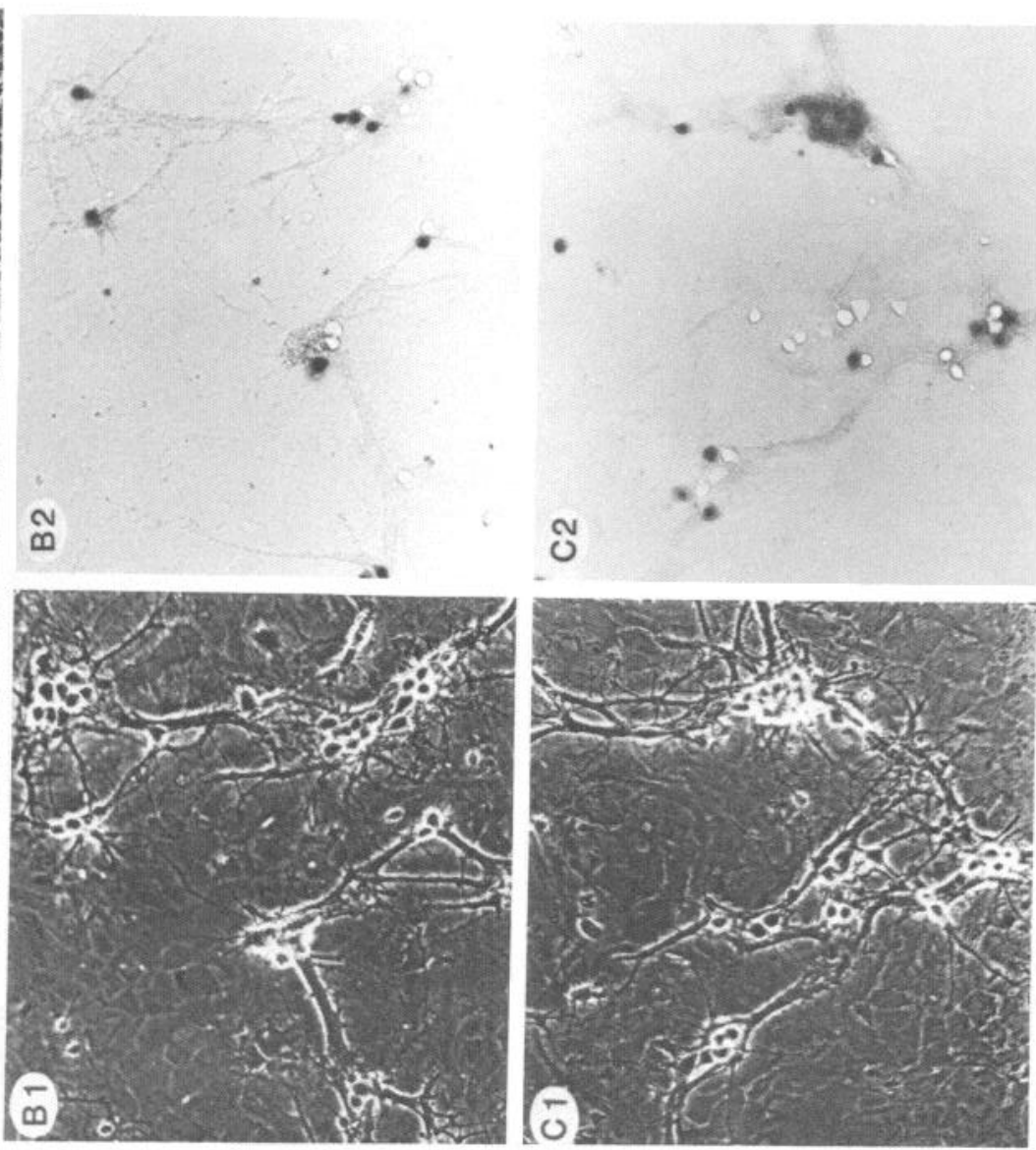

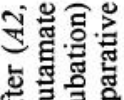

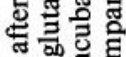

$\checkmark \pm$.

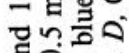

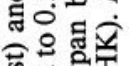

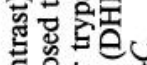

O

저ㅇㅝㅛ

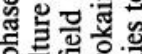

可包

ड़े

․ㅗㅇ.

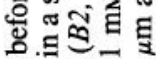

돌흥형응

I

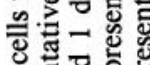

త⿹

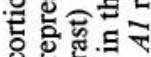

论

ㅇํㅇํㄹ

包.

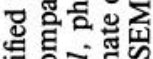

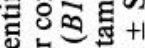

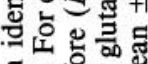

สิ

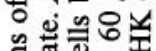

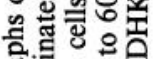

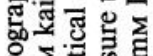

융령

这证

r웡ㅎㅇ

₹氙击

ㄴㅇㅇㄹㄹ

这势 ठ․ㅡㄹ In

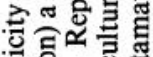
这舟要 을 ․․웡 号

击

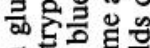

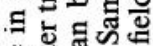

额 记

뭉

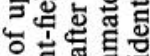

8 .

동훙

당 ₹

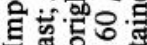

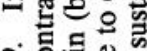

유ㅇㅖㅖ

今ั

部蒙 

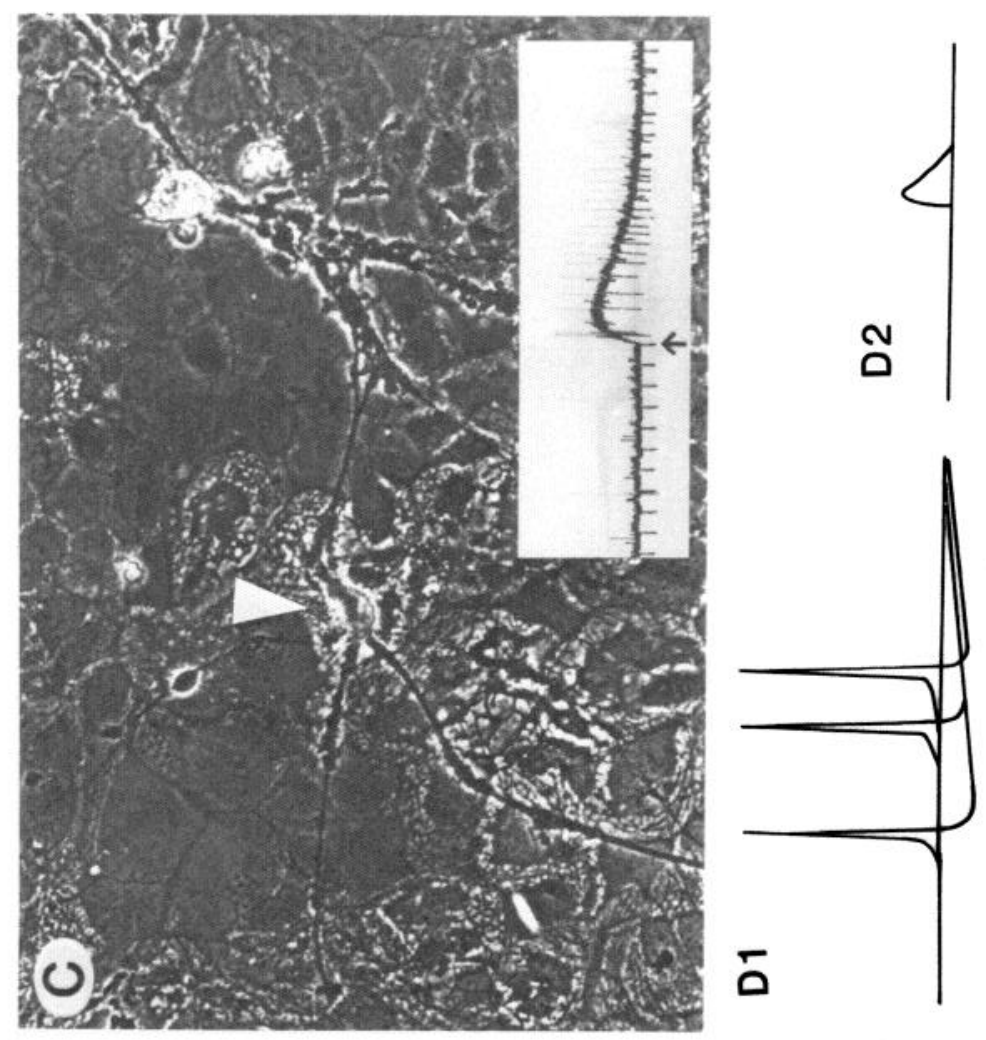

동 :

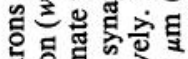

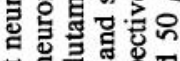

迅

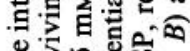

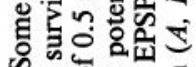

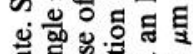

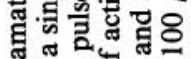

灵宁绻

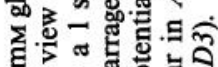

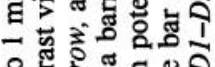

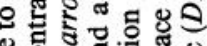

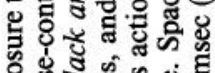

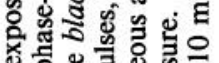

ख

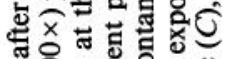

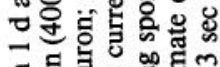

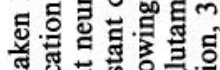

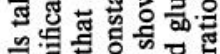

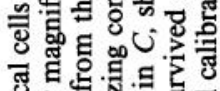

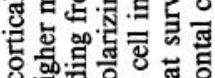

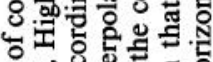

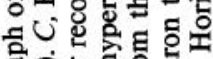

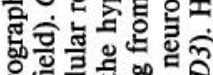

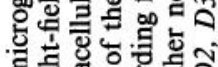

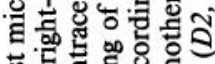

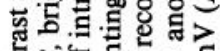

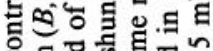

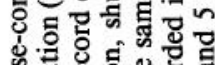

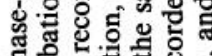

蛹 동

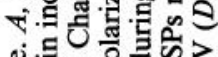

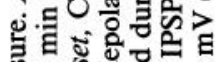

颌

这氖

䒕氙.

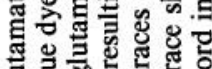
흐음 कo

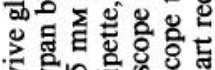

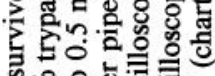

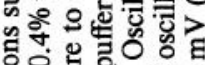

일

屯ํํ유.

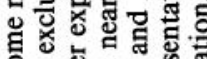

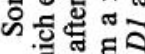

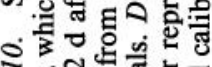

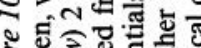

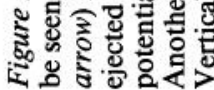

m 
reduced availability of membrane calcium conductances could be another parameter that is correlated with GNT resistance.

Note added in proof: We have now searched for these $\mathrm{NADPH}-\mathrm{d}(+)$ in our cortical cultures, and have found these cells to be selectively resistant to the toxicity of $N$-methyl-D-aspartate, but not to the toxicity of glutamate (Koh et al., 1986).

\section{References}

Bird, S. J., R. L. Gulley, R. J. Wenthold, and J. Fex (1978) Kainic acid injections result in degeneration of cochlear nucleus cells innervated by the auditory nerve. Science $202: 1087-1089$.

Biziere, K., and J. T. Coyle (1978) Influence of cortio-striatal afferents on striatal kainic acid neurotoxicity. Neurosci. Lett. 8: 303-310.

Booher, J., and M. Sensenbrenner (1972) Growth and cultivation of dissociated neurons and glial cells from embryonic chick, rat and human brain in flask cultures. Neurobiology 2: 97-105.

Brookes, N., and D. R. Burt (1980) Development of muscarinic receptor binding in spinal cord cell cultures and its reduction by glutamic and kainic acids. Dev. Neurosci. 3: 118-127.

Choi, D. W., and G. D. Fischbach (1981) GABA conductance of chick spinal cord and dorsal root ganglion neurons in cell culture. J. Neurophysiol. 45: 605-620.

Coyle, J. T., and R. Schwarcz (1976) Lesion of striatal neurones with kainic acid provides a model for Huntington's chorea. Nature 263: 244-246.

Coyle, J. T., S. J. Bird, R. H. Evans, R. L. Gulley, J. V. Nadler, W. J. Nicklas, and J. W. Olney (1981) Excitatory amino acid neurotoxins: Selectivity, specificity, and mechanisms of action. Neurosci. Res. Prog. Bull. 19: 331-427.

Crawford, J. M., and D. R. Curtis (1964) The excitation and depression of mammalian cortical neurons by amino acids. Br. J. Pharmacol. 23: 323-329.

Curtis, D. R., J. W. Phillis, and J. C. Watkins (1960) The chemical excitation of spinal neurons by certain acidic amino acids. J. Physiol. (Lond.) 150: 656-682.

DiChiara, G. D., and G. L. Gessa (1981) Glutamate as a neurotransmitter. Adv. Biochem. Psychopharmacol., Vol. 27.

Dichter, M. A. (1978) Rat cortical neurons in cell culture: Culture methods, cell morphology, electrophysiology, and synapse formation. Brain Res. 149: 279-293.

Duce, I. R., P. L. Donaldson, and P. N. R. Usherwood (1983) Investigations into the mechanism of excitant amino acid cytotoxicity using a well-characterized glutamatergic system. Brain Res. 263: 77-87.

Ferrante, R. J., N. W. Kowall, M. F. Beal, E. P. Richardson, E. D. Bird, and J. B. Martin (1985) Selective sparing of a class of striatal neurons in Huntington's disease. Science 230: 561-563.

Garthwaite, J. (1985) Cellular uptake disguises action of L-glutamate on N-methyl-D-aspartate receptors. Br. J. Pharmacol. 85: 297-307.

Hyndman, A. G. (1984) The effects of glutamate and kainate on cell proliferation in retinal cultures. Invest. Ophthalmol. Vis. Sci. 25:558563.

Johnston, G. A. R., S. M. E. Kennedy, and B. Twitchin (1979) Action of the neurotoxin kainic acid on high affinity uptake of L-glutamic acid in rat brain slices. J. Neurochem. 32: 121-127.

Koh, J., S. Peters, and D. W. Choi (1986) Neurons containing NADPHdiaphorase are selectively resistant to quinolinate toxicity. Science 234: 73-76.

Kohler, C., and R. Schwarcz (1983) Comparison of ibotenate and kainate neurotoxicity in rat brain: A histological study. Neuroscience 8: 819-835.
Krnjevic, K. (1974) Chemical nature of synaptic transmission in vertebrates. Physiol. Res. 54: 418-540.

Lucas, D. R., and J. P. Newhouse (1957) The toxic effect of sodium L-glutamate on the inner layers of the retina. Arch. Opthalmol. 58: 193-201.

Mangano, R. M., and R. Schwarcz (1983) Chronic infusion of endogenous excitatory amino acids into rat striatum and hippocampus. Brain Res. Bull. 10: 47-51.

McBean, G. J., and P. J. Roberts (1984) Chronic infusion of L-glutamate causes neurotoxicity in rat striatum. Brain Res. 290: 372-375.

McCarthy, K. D., and J. deVellis (1980) Preparation of separate astroglial and oligodendroglial cell cultures from rat cerebral tissue. J. Cell Biol. 85: 890-902.

McGeer, E. G., and P. L. McGeer (1976) Duplication of biochemical changes of Huntington's chorea by intrastriatal injections of glutamic and kainic acids. Nature 263: 517-519.

McLennan, H. (1976) The autoradiographic localization of $\mathrm{L}-\left[{ }^{3} \mathrm{H}\right]$ glutamate in rat brain tissue. Brain Res. 115: 139-144.

Nadler, J. V., B. W. Perry, and C. W. Cotman (1978) Intraventricular kainic acid preferentially destroys hippocampal pyramidal cells. $\mathrm{Na}$ ture 271: 676-677.

Nadler, J. V., B. W. Perry, C. Gentry, and C. W. Cotman (1980) Degeneration of hippocampal CA3 pyramidal cells induced by intraventricular kainic acid. J. Comp. Neurol. 192: 333-359.

Nitecka, L., E. Tremblay, G. Charton, J. P. Bouillot, M. L. Berger, and Y. Ben-Ari (1984) Maturation of kainic acid seizure-brain damage syndrome in the rat. II. Histopathological sequelae. Neuroscience 13: 1073-1094.

Olney, J. W. (1969) Brain lesion, obesity and other disturbances in mice treated with monosodium glutamate. Science 164: 719-721.

Olney, J. W. (1971) Glutamate-induced neuronal necrosis in the infant mouse hypothalamus. An electron microscopic study. J. Neuropathol. Exp. Neurol. 30: 75-90.

Olney, J. W. (1978) Neurotoxicity of excitatory amino acids. In Kainic Acid as a Tool in Neurobiology, E.G. McGeer, J.W. Olney, and P.L. McGeer, eds., pp. 95-121, Raven, New York.

Olney, J. W., O. L. Ho, and V. Rhee (1971) Cytotoxic effects of acidic and sulphur containing amino acids on the infant mouse central nervous system. Exp. Brain Res. 14: 61-76.

Plaitakis, A., S. Berl, and M. D. Yahr (1982) Abnormal glutamate metabolism in an adult-onset degenerative neurological disorder. Science 216: 193-196.

Rothman, S. (1984) Synaptic release of excitatory amino acid neurotransmitter mediates anoxic neuronal death. J. Neurosci. 4: 18841891.

Sanderson, C., and S. Murphy (1982) Glutamate binding in the rat cerebral cortex during ontogeny. Dev. Brain Res. 2: 329-339.

Schousboe, A. (1981) Transport and metabolism of glutamate and GABA in neurons and glial cells. Int. Rev. Neurobiol. 22: 1-45.

Schwarcz, R., D. Scholz, and J. T. Coyle (1978) Structure-activity relations for the neurotoxicity of kainic acid derivatives and glutamate analogues. Neuropharmacology 17: 145-151.

Simon, R. P., J. H. Swan, T. Griffiths, and B. S. Meldrum (1984) Blockade of $N$-methyl-D-aspartate receptors may protect against ischemic damage in the brain. Science 226: 850-852.

Sloviter, R. S. (1983) "Epileptic" brain damage in rats induced by sustained electrical stimulation of the perforant path. I. Acute electrophysiological and light microscopic studies. Brain Res. Bull. 10: 675-697.

Waelsch, H. (1951) Glutamic acid and cerebral function. Adv. Protein Chem. 6: 299-341.

Wieloch, T. (1985) Hypoglycemia-induced neuronal damage prevented by an $N$-methyl-D-aspartate antagonist. Science 230:681-683. 